DOI: $10.17957 / \mathrm{IJAB} / 15.1759$

http://www.fspublishers.org

\title{
Prevalence and Molecular Characterization of Anaplasma marginale in Cattle Population of Khyber Pakhtunkhwa Province, Pakistan
}

\author{
Muhammad Shoaib ${ }^{1}$, Muhammad Imran Rashid ${ }^{*}$, Haroon Akbar ${ }^{1}$, Ali Ahmad Sheikh ${ }^{2}$, Shahid Hussain Farooqi ${ }^{3}$, \\ Mumtaz Ali Khan ${ }^{4}$, Farhan Anwar Khan ${ }^{5}$ and Rajwali Khan ${ }^{6}$ \\ ${ }^{1}$ Department of Parasitology, University of Veterinary and Animal Sciences, Lahore, Pakistan \\ ${ }^{2}$ Department of Microbiology, University of Veterinary and Animal Sciences, Lahore, Pakistan \\ ${ }^{3}$ Department of Clinical Sciences, KBCMA, College of Veterinary and Animal Sciences, Narowal, Pakistan \\ ${ }^{4}$ Livestock and Dairy Development (Extension), (KP), Pakistan \\ ${ }^{5}$ College of Veterinary sciences, The University of Agriculture, Peshawar, Khyber Pakhtunkhwa (KP), Pakistan \\ ${ }^{6}$ Department of Livestock Management, Breeding and Genetics, The University of Agriculture Peshawar, Khyber \\ Pakhtunkhwa (KP), Pakistan \\ For correspondence: imran.rashid@uvas.edu.pk \\ Received 21 November 2020; Accepted 28 January 20201; Published 16 April 2021
}

\begin{abstract}
Anaplasmosis is a hemo-rickettsial disease of cattle and is most prevalent in tropical and subtropical regions of the world including Pakistan. This disease has been placed as one of the most economically important haemoparasitic diseases. The aim of the current study was to determine the molecular characterization and to assess the prevalence of Anaplasma marginale (A. marginale) infection in cattle and associated risk factors in three districts of Khyber Pakhtunkhwa (KP) province of Pakistan viz., Mardan, Kohat and Swat. The blood samples were collected conveniently from 434 tick-infested animals keeping the aseptic measures. A. marginale was identified from blood samples by microscopy and PCR. Sequencing and phylogenetic analysis of the sequenced isolates of this study showed close sequence similarity with the reported strains of USA, Thailand, Uganda, Uruguay, Zimbabwe, Philippines and China. Moreover, multiple sequence alignment of the 16S ribosomal RNA gene sequences of 5 different clones of the A. marginale depicts substantial variation in the genotypes of $A$. marginale found in different locations of KP. The prevalence of $A$. marginale infection was non-significantly associated $(P>0.05)$ with districts, season, breed, age and sex of cattle. The highest prevalence of $A$. marginale infection was recorded in district Swat (20.30\%) followed by Kohat (16.81\%) and Mardan (15.00\%) districts of KP. The prevalence of infection was highest in exotic breeds and their crosses, adults and female cattle. 10.70, 16.11, 46.70 and $26.70 \%$ were the prevalence of infection recorded for winter, spring, summer and autumn season, respectively. This study concludes that A. marginale infection is dominant in district Swat followed by Kohat and Mardan districts of KP province of Pakistan, respectively. (C) 2021 Friends Science Publishers
\end{abstract}

Key words: Prevalence; Anaplasmosis; Cattle; Sequencing; Phylogeny; Risk factors

\section{Introduction}

Anaplasma belongs to the rickettsial group of parasites which is an intraerythrocytic obligate bacteria responsible for bovine anaplasmosis and is transmitted by ticks (Inokuma 2007). Important species of the genus Anaplasma include Anaplasma centrale, A. marginale, $A$. phagocytophilum, A. ovis, A. platys and A. bovis. A. bovis is found both in wild and domestic animals in different parts of the world (Liu et al. 2012). A. centrale and A. marginale cause bovine anaplasmosis (Minjauw and McLeod 2003; Kocan et al. 2004). Gall sickness is another name of the disease. Almost all domesticated animals like buffaloes, cattle, goats, sheep as well as wild ruminants are affected by this disease. Bovine anaplasmosis is most commonly caused by $A$. marginale. It is a highly pathogenic disease characterized by weakness, anorexia, weight loss, depression, fever, jaundice, hemolytic anemia, decreased milk production, abortion and death. Cattle are more susceptible to infection than buffaloes and the disease causes high mortality in livestock (Rajput et al. 2005; Kocan et al. 2010). Transmission of the disease occurs mostly by ticks, about 20 ticks species are involved in the transmission of the disease (Marchette and Stiller 2018). Notable ticks species are Hyalomma species, Rhipicephalus species, Ixodes species, Boophilus species and Dermacentor species (Jongejan and Uilenberg 2004). Anaplasmosis occurs mainly in hot, humid and rainy seasons due to an abundance of ticks (El-Metenawy 2000). Surgical blades and contaminated needles are the mechanical sources of

To cite this paper: Shoaib M, MI Rashid, H Akbar, AA Sheikh, SH Farooqi, MA Khan, FA Khan, R Khan (2021). Prevalence and Molecular characterization of Anaplasma marginale in cattle population of Khyber Pakhtunkhwa province, Pakistan. Intl J Agric Biol 25:1016-1023 
transmission of the disease. It is estimated that globally tickborne diseases produce losses ranging from 13.9-18.7 billion US\$ per year affecting $80 \%$ population of cattle (Ghosh et al. 2007). Anaplasmosis is one of the global importance diseases and is prevalent in developing countries like Zambia where livestock faces some serious challenges from tick-borne diseases especially anaplasmosis (Makala $e t$ al. 2003; Minjauw and McLeod 2003). Bovine anaplasmosis is highly prevalent in Africa and Asia due to the vast tick's movement and global warming (Jonsson and Reid 2000).

Anaplasmosis is a hemo-rickettsial disease of cattle and is highly prevalent in tropical and subtropical regions of the world including Pakistan (Dumler et al. 2001; Atif et al. 2013; Iqbal et al. 2019). It is one of the most prevalent hemoparasitic infections in Pakistan affecting bovines and its prevalence is $4-75.5 \%$ (Khan et al. 2004). It is a major health issue for livestock and cattle population in particular in Khyber Pakhtunkhwa (Nieto et al. 2012; Nasreen et al. 2016; Shah et al. 2017; Farooqi et al. 2018; Khan et al. 2019; Turi et al. 2019). This project aimed to find out the prevalence, molecular diagnosis, and characterization of $A$. marginale in the KP province of Pakistan.

\section{Materials and Methods}

\section{Study area}

This study was carried out from January 2018 to March 2019. The blood samples were collected from different cattle breeds of three districts of KP province viz., Mardan, Kohat and Swat as shown by Fig. 1. 434 blood samples were collected by the convenient method of sampling (Fanzana and Srunvet al. 2001). A total of 160, 131 and 143 blood samples were collected from Mardan, Kohat and Swat districts, respectively. A pre-tested data collection form was used having information about the data regarding date of sample collection, details about the animal (age, breed and sex) and place of the collection (Thrusfield 2007). About $5 \mathrm{~mL}$ of blood was collected from the jugular vein of cattle into vacutainers containing EDTA as an anticoagulant for the preservation of blood samples. Then these samples were shifted to parasitology laboratory UVAS, Lahore and were stored at $-20^{\circ} \mathrm{C}$. GPS data was processed in MS Excel and then imported into ArcGIS 10.2. The sampling sites were geo-visualized in the form of point map. Then same points were populated on the map of Pakistan to present the spatial distribution of samples.

\section{Microscopic examination}

Thin smears were prepared on the spot for better results. The smears were fixed with absolute ethanol and stained with Giemsa in the laboratory of Parasitology, University of Veterinary and Animal Sciences Lahore. The smears were examined at 100x magnification under a compound microscope for the presence of A. marginale (Kumar et al. 2015).

\section{Molecular examination}

Molecular identification of A. marginale was carried out through polymerase chain reaction (Roy et al. 2018). The DNA was extracted by using a DNA extraction kit (cat. No: FABGK001-2) by the method used by (d'Oliveira et al. 1995). The purity and concentration of extracted DNA were checked by Nanodrop and was stored at $-20^{\circ} \mathrm{C}$. The Polymerase chain reaction (PCR) was performed as described by (Gubbels et al. 1999). The extracted DNA samples were subjected to PCR which amplified the $16 \mathrm{~S}$ rRNA gene of Anaplasma by using general primer EHR. This general primer consists of a forward primer EHR16SD (5'- GGTACCTACAGAAGAAGTCC-3') and a reverse primer EHR-16SR (5'TAGCACTCATCGTTTACAGC-3') and this set of primers targeted the 16S ribosomal RNA gene of Anaplasma (Tay et al. 2014). Master mix solution for PCR was prepared, $20 \mu \mathrm{L}$ reaction mixture having $1.5 \mathrm{U}$ of Taq DNA polymerase was taken and $2 \mu \mathrm{L}$ of extracted DNA, 25 pmol of each primer, $200 \mathrm{~m} M$ of each dNTP, $5 \mu \mathrm{L}$ of $10 \mathrm{X}$ PCR buffer and $1.5 \mathrm{~m} M \mathrm{MgCl}_{2}$ (Promega, Madison, W.I., U.S.A.) were added. An initial denaturation step was the first step of the PCR reaction cycle which was set at $94^{\circ} \mathrm{C}$ for 5 min followed by a second cycle of denaturation (40 cycles) at $94^{\circ} \mathrm{C}$ for $30 \mathrm{~s}$, then annealing for $30 \mathrm{~s}$ at $55^{\circ} \mathrm{C}$ and then extension for one $\min$ at $72^{\circ} \mathrm{C}$. The final extension was done for $5 \mathrm{~min}$ at $72^{\circ} \mathrm{C}$ which was followed by a hold step at $4^{\circ} \mathrm{C}$. In each PCR experiment, a control positive (Agricultural Research Service, Animal Disease Research Unit, Department of Agriculture, Pullman, W.A., U.S.A.) and control negative were included. Gel electrophoresis was used for checking of positive bands against a standard molecular ladder of $100 \mathrm{bp}$ on ethidium bromide stained 1.5\% agarose gel at 200 amperes, $120 \mathrm{~V}$ for $30 \mathrm{~min}$ (Fig. 3). The bands for A. marginale were observed at $345 \mathrm{bp}$ level. The positive bands were then cut and were considered for sequencing for further confirmation.

\section{Sequencing}

The PCR bands of haemoparasites were cut on $1.5 \%$ agarose gel using a cutter. The gel extraction kit (WizPrep $^{\mathrm{TM}}$ Gel/PCR purification kit, Ref. W70150-300) was then used for the extraction and purification of DNA bands from gel following the directions of the manufacturer. By using gel electrophoresis DNA concentration was checked and the DNA samples were sent to $1^{\text {st }}$ base DNA sequencing services, Singapore for sequencing. The phylogenetic tree was constructed for the isolates identical to $A$. marginale by using MEGA 7 at maximum likelihood algorithm and with bootstrapping at 1000 replications (Fig. 4). 


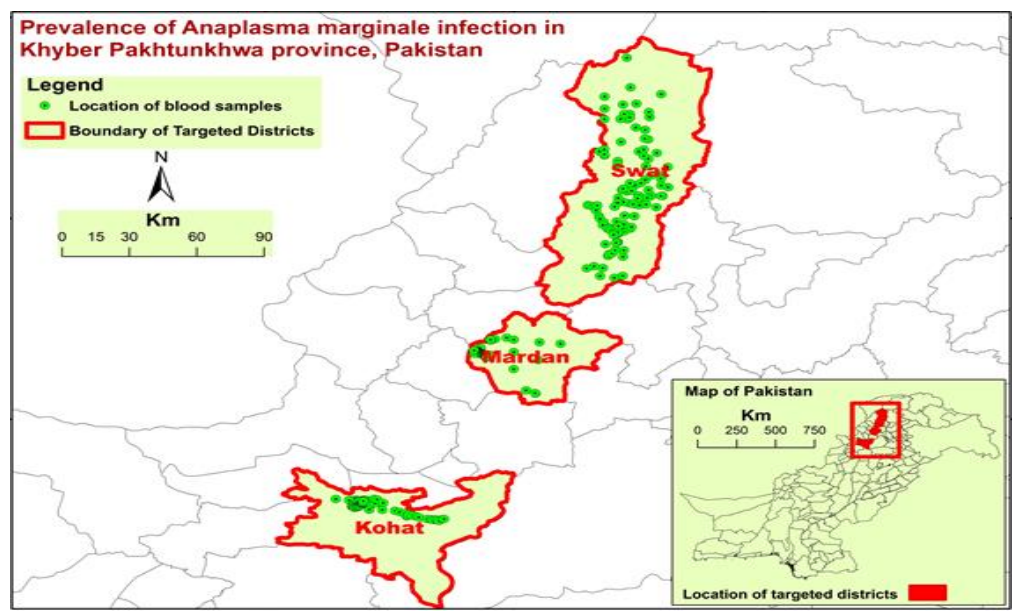

Fig. 1: Map of Pakistan showing sampling sites in targeted districts of KP

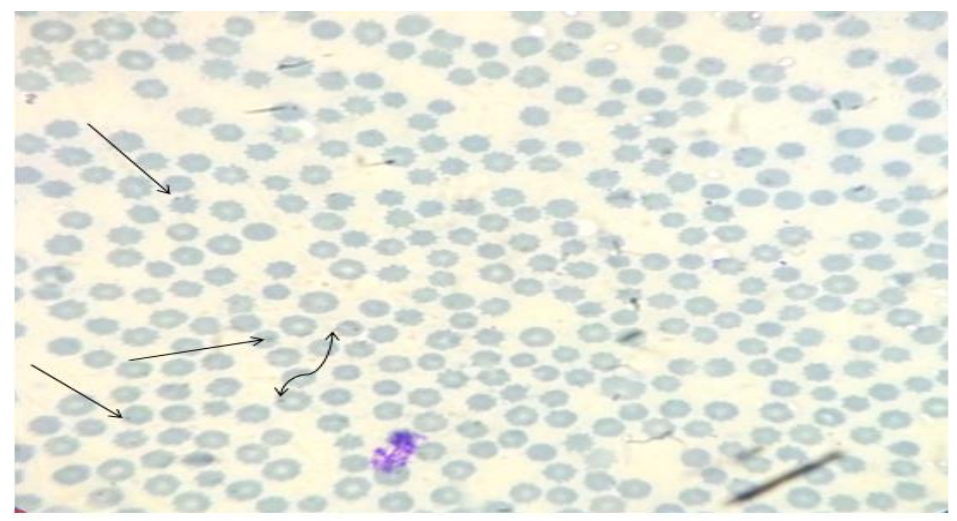

Fig. 2: Figure shows A. marginale like intracellular bodies in Giemsa's stained thin blood smear (indicated by arrows)

\section{Statistical analysis}

Chi-square test was used to analyze the prevalence of Anaplasma species data using SPSS version 20. $P$-value < 0.05 was taken as level of significance for the achievement of a 95\% confidence interval (Farooqi et al. 2018).

\section{Results}

Microscopically thin blood smears were prepared and checked for the presence of intraerythrocytic inclusions bodies resembling A. marginali (Fig. 2). Microscopic examination showed that there were $10.00,12.98$ and $17.48 \%$ positive cases for A. marginale infection in cattle of Mardan, Kohat and Swat districts, respectively (Table 1). PCR showed $15.00,16.79$ and $20.28 \%$ positive cases in Mardan, Kohat and Swat districts, respectively (Table 2). It was clear from the results that PCR is a more sensitive and accurate method for the diagnosis of $A$. marginale infection as shown by Table 3 . The PCR products of A. marginale were subjected to sequencing. BLAST and CLUSTAL W alignments were used for the analysis of these sequences.
The resulted sequenced nucleotide after BLAST indicated the sequence similarity with the $16 \mathrm{~S}$ ribosomal RNA gene of $A$. marginale. For comparison, the nucleotide sequences of these organisms were aligned from the NCBI database. The amplicons showed 96-99\% similarity with the sequences of nucleotide for this gene which was deposited in GenBank. Five sequence products of A. marginale from $\mathrm{KP}$ with the allotted accession numbers from NCBI i.e., MT893360.1 A. marginale (KP-1 Pak), MT893363.1 A. marginale (KP-2 Pak), MT893366.1 A. marginale (KP-3 Pak), MT893368.1 A. marginale (KP-4 Pak) and MT893370.1 A. marginale (KP-5 Pak) were used for the construction of phylogenetic tree as shown by Fig. 4 (Tamura 1992; Kumar et al. 2016).

It was observed from the results that breed, age and sex of cattle were non-significantly associated $(P>0.05)$ with $A$. marginale infection among the studied districts. The district wise prevalence of infection was recorded highest in district Swat followed by Kohat and Mardan districts, respectively. The results showed that the rate of infection was higher in exotic breeds (Friesians and crossbred) as compared to local breeds (Achi and Sahiwal) of cattle. The adult cattle were 


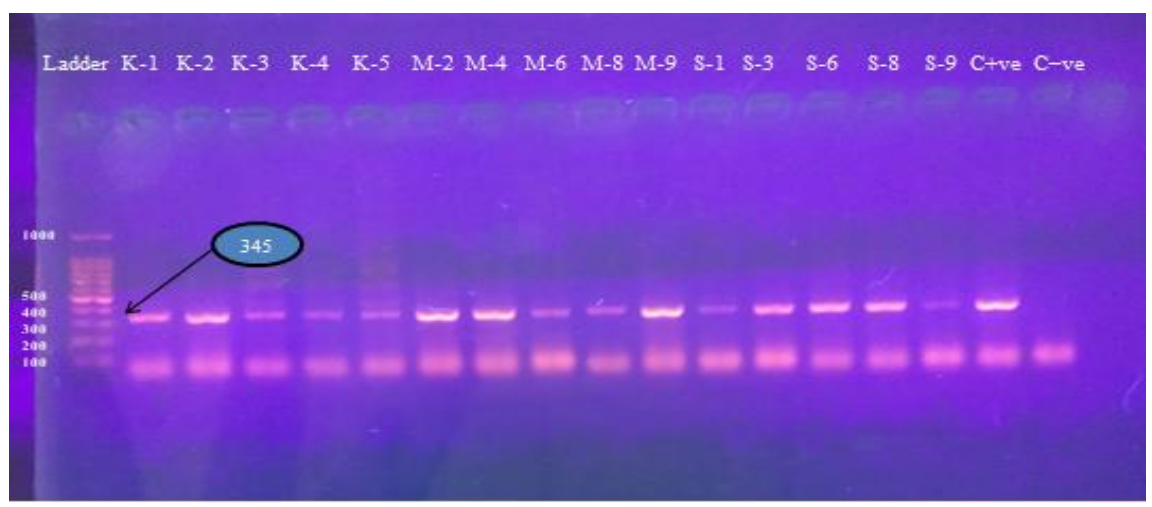

Fig. 3: PCR results for A. marginale. It shows gel electrophoresis after PCR having clear bands of an amplified 345 base pair DNA fragment of $A$. marginale against a marker of known molecular weight of 100 base pair. The lane Ladder shows a molecular weight marker. Positive samples of $A$. marginale are shown in lane just after the lane ladder for Kohat, Mardan and Swat districts, respectively. Lane $\mathrm{C}+\mathrm{ve}$ shows control positive (A. marginale) while lane $\mathrm{C}-\mathrm{ve}$ shows control negative

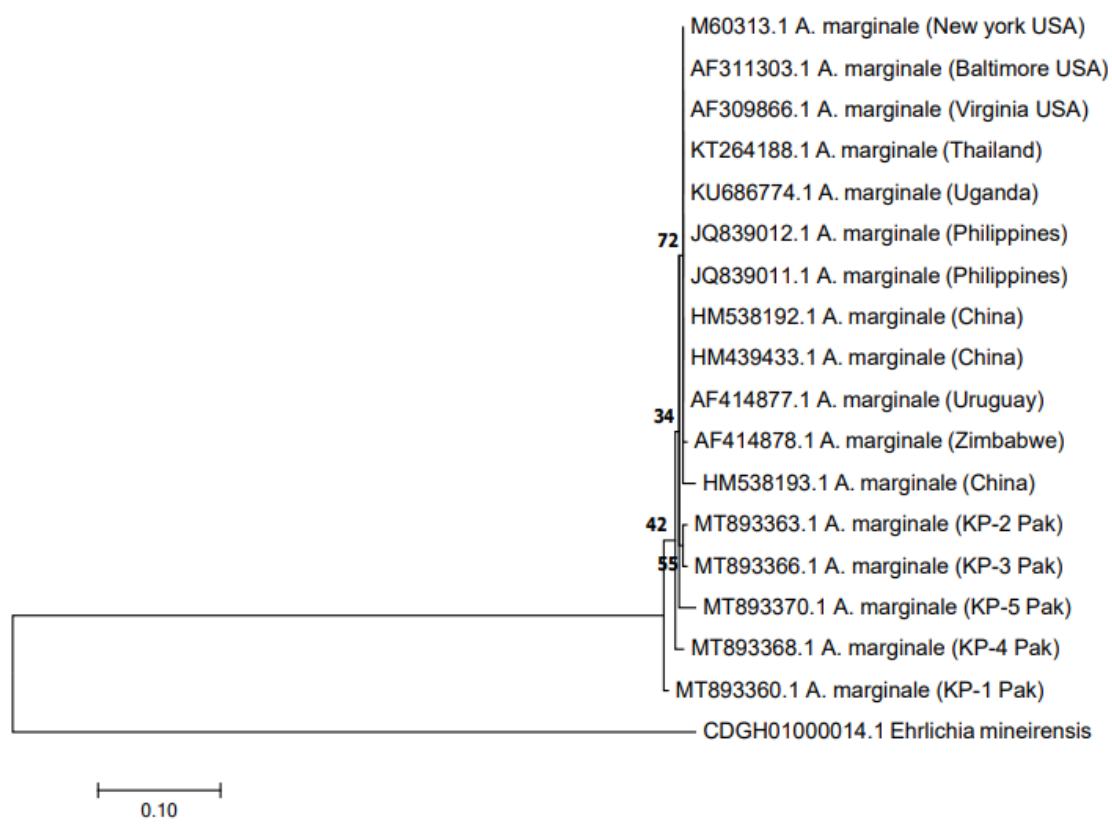

Fig. 4: It shows dendrogram representing the phylogenetic locations of genotypes of A. marginale based on the partial sequencing of $16 \mathrm{~S}$ ribosomal RNA gene. MT893360.1 A. marginale (KP-1 Pak), MT893363.1 A. marginale (KP-2 Pak), MT893366.1 A. marginale (KP-3 Pak), MT893368.1 A. marginale (KP-4 Pak) and MT893370.1 A. marginale (KP-5 Pak) represent the gene sequences from this study with their allotted accession numbers from Genbank. The published sequences of $A$. marginale from the Genbank database were used in the analysis process. Ehrlichia mineirensis (CDGH01000014.1) was used as an outgroup for this study

affected more by the A. marginale infection as compared to young animals. Similarly, the prevalence of infection was recorded higher in female animals as compared to males as shown by Table $4.10 .70,16.11,46.70$ and $26.70 \%$ were the prevalence of infection recorded for winter, spring, summer and autumn season, respectively. It was observed from the phylogenetic tree of $A$. marginale (Fig. 4) that the sequence isolates of this study were closely associated with each other and they showed sequence similarities with the reported strains of USA (M60313.1, AF311303.1, AF309866.1), Thailand (KT264188.1), Uganda (KU686774.1),
Philippines (JQ839012.1, JQ839011.1), China (HM538192.1, HM439433.1, HM538193.1), Uruguay (AF414877.1) and Zimbabwe (AF414878.1). Multiple sequence alignment of the $16 \mathrm{~S}$ ribosomal RNA gene sequences of 5 different clones of $A$. marginale depicts substantial variation in the genotypes of $A$. marginale found in different locations of KP (Fig. 5).

\section{Discussion}

Anaplasmosis is distributed throughout the world affecting 
cattle populations especially in developing countries where the disease is highly endemic resulting in huge economic losses (Futse et al. 2003; Rodríguez et al. 2009). There is insufficient data of tick-borne diseases especially anaplasmosis in the KP province of Pakistan, even though livestock faces major challenges from these tick-borne diseases (Khan et al. 2004). The current study relates to the seasonal prevalence and molecular characterization of $A$. marginale in the KP province of Pakistan. The blood was screened by microscopy for $A$. marginale. The slides showed intraerythrocytic inclusion bodies resembling $A$. marginale under a light microscope. It correlates with the findings of Ahmad and Hasmi (2007), Atif et al. (2012) and Maharana et al. (2016). It was clear from the results that polymerase chain reaction gave better results in the identification of A. marginale than microscopy, so it was a more accurate and sensitive method than microscopy. It is in accordance with the findings of Khattak et al. (2012) and Saad et al. (2015) who confirmed PCR as a more sensitive technique for the diagnosis of haemoparasitic infection.

The prevalence of $A$. marginale infection in three districts of KP was recorded by using the Chi-Square test. It was observed that the difference in the prevalence of infections was non-significant $(P>0.05)$ in the studied districts. The highest prevalence was recorded in district Swat followed by Kohat and Mardan districts respectively. These findings correlate with the work done by Rajput et al. (2005); Atif et al. (2013); Farooqi et al. (2018).

The breeds of the cattle were checked for the presence of $A$. marginale infection and it was observed that the prevalence of infection was non-significantly $(P>0.05)$ associated with breeds of cattle in the studied districts. The results showed a higher prevalence of infection in exotic breeds and their crosses as compared to local breeds of cattle. The findings of this study are in accordance with the studies done by Chowdhury et al. (2006); Atif et al. (2012); Farooqi et al. (2018); Khan et al. (2019) who have also reported a higher prevalence of Anaplasma infection in exotic and crossbred animals as compared to local breeds of animals. This is because the exotic breeds and their crosses are in a state of more danger to tick infestation (Bock et al. 1997).

A. marginale infection was checked in cattle of KP province according to their age groups. It was observed that there was a non-significant $(P>0.05)$ association between the different age groups of cattle and the prevalence of infection in the studied districts. The results showed a higher A. marginale infection in adults than young cattle. Khan et al. (2004) also reported a non-significant relationship $(P>$ $0.05)$ between the prevalence of blood parasites of bovine and age groups and they observed higher prevalence in adults $(30.76 \%)$ than young animals $(23.07 \%)$ which are in accordance with this study. Atif et al. (2013) also reported higher anaplasmosis in adults than in young cattle. The reason for higher parasitic infection in adults than young animals is the higher immunity of young animals due to the
Table 1: Microscopic examination of blood for A. marginale

\begin{tabular}{llll}
\hline District & Positive $\mathrm{n}(\%)$ & Negative $\mathrm{n}(\%)$ & Total \\
\hline Mardan & $16(10.00)$ & $144(90.00)$ & 160 \\
Kohat & $17(12.98)$ & $114(87.02)$ & 131 \\
Swat & $25(17.48)$ & $118(82.52)$ & 143 \\
\hline
\end{tabular}

Table 2: Molecular (PCR) examination of blood for A. marginale

\begin{tabular}{lllll}
\hline S. No. & District & Positive $(\%)$ & Negative n(\%) & Total \\
\hline 1 & Mardan & $24(15.00)$ & $136(85.00)$ & 160 \\
2 & Kohat & $22(16.79)$ & $109(83.21)$ & 131 \\
3 & Swat & $29(20.28)$ & $114(79.72)$ & 143 \\
\hline
\end{tabular}

Table 3: Comparison between results of microscopy and PCR for A. marginale

\begin{tabular}{llll}
\hline S. No. & District & Microscopy n $(\%)$ & PCR n $(\%)$ \\
\hline 1 & Mardan & $16(10.00)$ & $24(15.00)$ \\
2 & Kohat & $17(12.98)$ & $22(16.79)$ \\
3 & Swat & $25(17.48)$ & $29(20.28)$ \\
\hline
\end{tabular}

presence of foetal haemoglobin in their circulatory blood system (Ristic and Levy 1981). On the other hand, Nazar et al. (2018) and Khan et al. (2019) reported a higher prevalence of anaplasmosis in younger stock as compared to adult cattle which mismatches with the results of this study.

The sex of cattle was checked against the prevalence of A. marginale infection in the study districts. It was observed from the results that there was a non-significant $(P$ $>0.05)$ association between the prevalence of infection and sex of the cattle. It was clear from the results that the prevalence of infection was higher in females than male cattle. This study matches with the findings of Rajput et al. (2005) and Atif et al. (2012) who also reported higher anaplasmosis in females than male animals in their studies. Hormonal imbalances and immunosuppression in female animals are some of the reasons for the higher prevalence of haemoparasitic infections in females than male animals (Kocan et al. 2003). The results of this study showed that $A$. marginale infection was prevalent in different seasons of the year in KP province of Pakistan. Similar studies about the seasonal prevalence of anaplasmosis in $\mathrm{KP}$ province were conducted by Nasreen et al. (2016) and Khan et al. (2019)

Sequencing and phylogenetic analysis of $A$. marginale was studied in the KP province. It was observed from the phylogenetic tree of A. marginale (Fig. 4) that the sequence isolates of this study were closely associated with each other and they showed sequence similarity with the reported strains of USA, Thailand, Uganda, Philippines, China, Uruguay and Zimbabwe. Moreover, multiple sequence alignment of the $16 \mathrm{~S}$ ribosomal RNA gene sequences of 5 different clones of the A. marginale depicts substantial variation in the genotypes of $A$. marginale found in different locations of KP (Khan et al. 2020). Liu et al. (2005); Ferrolho et al. (2016); Byaruhanga et al. (2018) have conducted similar studies for the sequencing and phylogenetic characterization of $A$. marginale which correlate with this study. The importation 
Table 4: Prevalence of A. marginale infection according to breed, age and sex of cattle

\begin{tabular}{|c|c|c|c|c|c|c|c|}
\hline \multicolumn{2}{|c|}{ Parameter } & Mardan $\mathrm{n}(\%)$ & Kohat n(\%) & Swat n(\%) & Total (n\%) & Chi-square value & $P$-value \\
\hline \multirow{4}{*}{ Breed } & District wise & $24(15.00)$ & $22(16.81)$ & $29(20.30)$ & $75(17.30)$ & 1.504 & 0.472 \\
\hline & Friesian & $06(17.10)$ & $03(17.60)$ & $08(25.00)$ & $17(20.21)$ & 0.728 & 0.695 \\
\hline & Crossbreed & $12(17.41)$ & $14(21.90)$ & $12(17.41)$ & $38(18.80)$ & 0.576 & .750 \\
\hline & Sahiwal & 00 & 00 & $03(33.30)$ & $03(09.70)$ & 8.119 & 0.017 \\
\hline \multirow[t]{2}{*}{ Age } & Young & $06(17.60)$ & $02(5.91)$ & $06(18.80)$ & $14(14.0)$ & 2.836 & 0.242 \\
\hline & Adult & $18(14.30)$ & $20(20.61)$ & $23(20.70)$ & $61(18.31)$ & 2.145 & 0.342 \\
\hline \multirow[t]{2}{*}{ Sex } & Male & $05(10.40)$ & $04(09.31)$ & $04(10.30)$ & $13(10.00)$ & 0.035 & 0.982 \\
\hline & Female & $19(17.00)$ & $18(20.51)$ & $25(24.00)$ & $62(20.41)$ & 1.662 & 0.436 \\
\hline
\end{tabular}

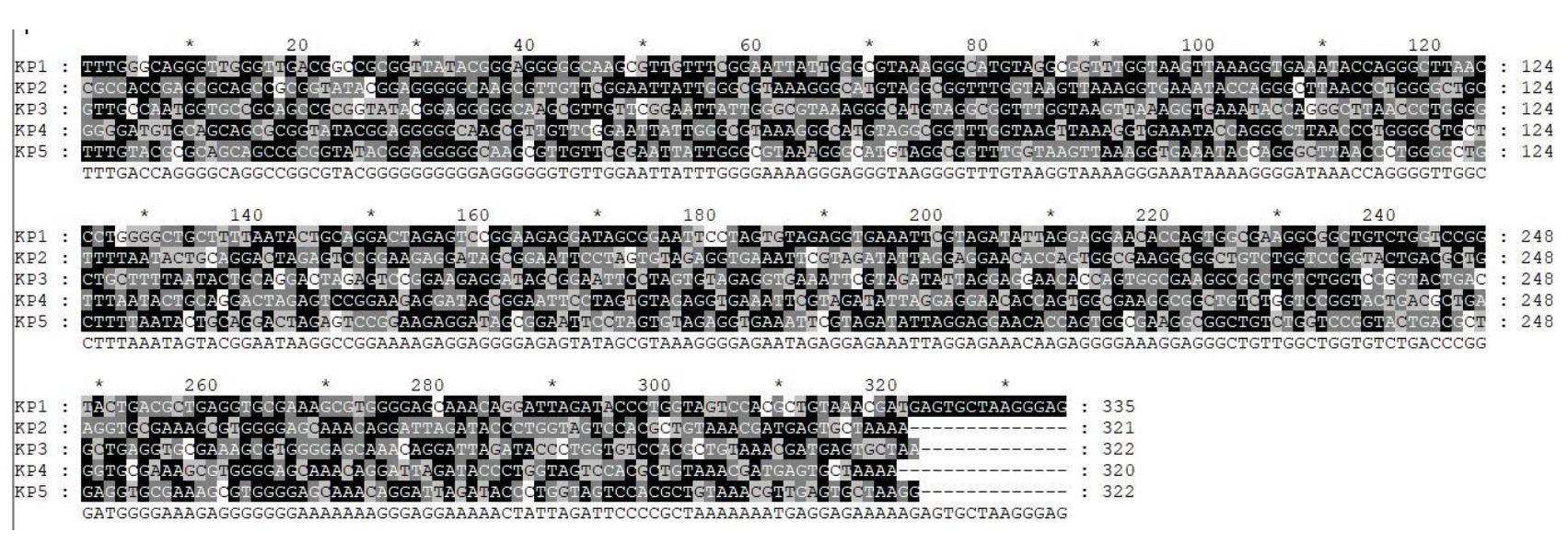

Fig. 5: The multiple sequence alignment of sequences of 5 clones of A. marginale viz., MT893360.1 A. marginale (KP-1 Pak), MT893363.1 A. marginale (KP-2 Pak), MT893366.1 A. marginale (KP-3 Pak), MT893368.1 A. marginale (KP-4 Pak) and MT893370.1 A. marginale (KP-5 Pak) based on the partial sequencing of 16S ribosomal RNA gene. The conservation level is denoted by background shading of the sequences "black" shows $100 \%$ conservation, the "gray with black" shows $80 \%$ conservation "grey with white" shows $60 \%$ conservation and "white" reflects no conservation

of livestock especially the live cattle from different regions of the world is the main reason for sequence similarities of the local and globally found haemoparasites (Rjeibi et al. 2018).

\section{Conclusion}

This study concludes that $A$. marginale infection was most prevalent in district Swat followed by Kohat and Mardan districts of KP province respectively. Prevalence of anaplasmosis was non-significantly $(P>0.05)$ associated with districts, season, breed, age and sex of cattle. The prevalence of infection was highest in exotic breeds and their crosses, adults and female animals. Phylogenetic analysis of A. marginale showed close sequence homology with the reported strains of different countries of the world like USA, Thailand, Uganda, Uruguay, Zimbabwe, Philippines and China. 5 different clones of the $A$. marginale found in different locations of KP showed genetic variations in the target sequence.

\section{Acknowledgement}

The authors are thankful to all veterinary officers and their staff for helping in the collection of blood samples.

\section{Author Contributions}

Manuscript write-up, data analysis and most of the experiments were performed by MS. MAK and FAK helped in the collection of blood samples from targeted districts. SHF helped in microscopy and PCR examinations in the laboratory. RW helped at review stage of article. MIR, HA and AAS helped in drafting of the research article and supervised the work.

\section{Conflicts of Interest}

All other authors declare no conflicts of interest

\section{Data availability}

Data presented in this study will be available on fair request to the corresponding author.

\section{Ethics Approval}

The experiments were carried out in accordance with the guidelines issued by the Animal Ethics Committee of University of Veterinary and Animal Sciences, Lahore, Pakistan. 
Shoaib et al. / Intl J Agric Biol, Vol 25, No 5, 2021

\section{References}

Ahmad N, H Hashmi (2007). A comparative study on the incidence of ticks and ticks borne diseases on local and crossbred cattle in Malakand agency. J Anim Plant Sci 17:56-58

Atif FA, M Khan, T Roheen, F Muhammad, M Younus, M Avais, S Ullah (2013). Seroprevalence of Anaplasma marginale infection among cattle from three districts of the Northern Punjab, Pakistan. J Anim Plant Sci 23:995-998

Atif FA, MS Khan, HJ Iqbal, GM Arshad, E Ashraf, S Ullah (2012). Prevalence of Anaplasma marginale, Babesia bigemina and Theileria annulata infections among cattle in Sargodha District, Pakistan. Afr J Agric Res 7:3302-3307

Bock R, AD Vos, T Kingston, D McLellan (1997). Effect of breed of cattle on innate resistance to infection with Babesia bovis, B. bigemina and Anaplasma marginale. Aust Vet $J$ 75:337-340

Byaruhanga C, NE Collins, DL Knobel, ZT Khumalo, ME Chaisi, MC Oosthuizen (2018). Molecular detection and phylogenetic analysis of Anaplasma marginale and Anaplasma centrale amongst transhumant cattle in north-eastern Uganda. Ticks Tick Borne Dis 9:580-588

Chowdhury S, M Hossain, S Barua, S Islam (2006). Occurrence of common blood parasites of cattle in Sirajgonj sadar area of Bangladesh. Bangl $J$ Vet Med 4:143-145

d'Oliveira C, MVD Weide, MA Habela, P Jacquiet, F Jongejan (1995). Detection of Theileria annulata in blood samples of carrier cattle by PCR. J Clin Microbiol 33:2665-2669

Dumler JS, AF Barbet, C Bekker, GA Dasch, GH Palmer, SC Ray, Y Rikihisa, FR Rurangirwa (2001). Reorganization of genera in the families Rickettsiaceae and Anaplasmataceae in the order Rickettsiales: Unification of some species of Ehrlichia with Anaplasma, Cowdria with Ehrlichia and Ehrlichia with Neorickettsia, descriptions of six new species combinations and designation of Ehrlichia equi and'HGE agent'as subjective synonyms of Ehrlichia phagocytophila. Intl J Syst Evol Microbiol 51:2145-2165

El-Metenawy T (2000). Prevalence of blood parasites among cattle at the central area of Saudi Arabia. Vet Parasitol 87:231-236

Fanzana BM, EA Srunv (2001). A venue based method for sampling hardto-reach populations. Publ Health Rep 116:216-222

Farooqi SH, M Ijaz, MI Rashid, H Nabi, S Islam, AI Aqib, K Hussain, A Khan, SNB Rizvi, S Mahmood (2018). Molecular epidemiology of bovine anaplasmosis in Khyber Pakhtunkhwa, Pakistan. Trop Anim Health Prod 50:1591-1598

Ferrolho J, S Antunes, AS Santos, R Velez, L Padre, A Cabezas-Cruz, MM Santos-Silva, A Domingos (2016). Detection and phylogenetic characterization of Theileria spp. and Anaplasma marginale in Rhipicephalus bursa in Portugal. Ticks Tick Borne Dis 7:443-448

Futse JE, MW Ueti, DP Knowles, GH Palmer (2003). Transmission of Anaplasma marginale by Boophilus microplus: Retention of vector competence Boophilus microplus: Retention of vector competence. $J$ Clin Microbiol 41:3829-3834

Ghosh S, GC Bansal, SC Gupta, D Ray, MQ Khan, H Irshad, M Shahiduzzaman, U Seitzer, JS Ahmed (2007). Status of tick distribution in Bangladesh, India and Pakistan. Parasitol Res 101:207-216

Gubbels J, AD Vos, MVD Weide, J Viseras, L Schouls, ED Vries, F Jongejan (1999). Simultaneous detection of Bovine Theileria and Babesia species by reverse line blot hybridization. J Clin Microbiol 37:1782-1789

Inokuma H (2007). Vectors and Reservoir Hosts of Anaplasmataceae. In: Handbook of Rickettsial diseases, p:199. Raoult D and P Parola (Eds.): CRC press, Boca Raton, Florida, USA

Iqbal N, MU Mukhtar, J Yang, MS Sajid, Q Niu, G Guan, Z Liu, H Yin (2019). First molecular evidence of Anaplasma bovis and Anaplasma phagocytophilum in bovine from central Punjab, Pakistan. Pathogens 8:155-162

Jongejan F, G Uilenberg (2004). The global importance of ticks. Parasitology. 129:3-14
Jonsson N, S Reid (2000). Global climate change and vector borne diseases. Vet $\mathrm{J} 2: 87-89$

Khan M, A Zahoor, M Jahangir, MA Mirza (2004). Prevalence of blood parasites in cattle and buffaloes. Pak Vet J 24:193-194

Khan NU, MS Sarwar, S Ayaz, H Ali, A Ali, I Khan, MA Khan, AU Khan, M Hussain, M Ali (2019). Prevalence and risk factors analysis associated with anaplasmosis in symptomatic cattle under field conditions in southern Khyber Pakhtoonkhwa, Pakistan. Pure Appl Biol 8:2119-2127

Khan R, SHA Raza, H Guo, W Xiaoyu, W Sen, SM Suhail, A Rahman, I Ullah, AH Abd El-Aziz, Z Manzari (2020). Genetic variants in the TORC2 gene promoter and their association with body measurement and carcass quality traits in Qinchuan cattle. PLoS One 15; Article $\mathrm{e} 0227254$

Khattak R, M Rabib, Z Khan, M Ishaq, H Hameed, A Taqddus, M Faryal, S Durranis, Q Gillani, R Allahyar (2012). A comparison of two different techniques for the detection of blood parasite, Theileria annulata, in cattle from two districts in Khyber Pukhtoon Khwa Province (Pakistan). Parasite. J Soc Franç Parasitol 19:91-95

Kocan KM, JDL Fuente, EF Blouin, JF Coetzee, S Ewing (2010). The natural history of Anaplasma marginale. Vet Parasitol 167:95-107

Kocan KM, JDL Fuente, EF Blouin, JC Garcia-García (2004). Anaplasma marginale (Rickettsiales: Anaplasmataceae): Recent advances in dening hostpathogen adaptations of a tick-borne rickettsia Parasitology 129:285-300

Kocan KM, JDL Fuente, AA Guglielmone, RD Meléndez (2003). Antigens and alternatives for control of Anaplasma marginale infection in cattle. Clin Microbiol Rev 16:698-712

Kumar S, G Stecher, K Tamura (2016). MEGA7: Molecular evolutionary genetics analysis version 7.0 for bigger datasets. Mol Biol Evol 33:1870-1874

Kumar T, N Sindhu, G Charaya, A Kumar, P Kumar, G Chandratere, D Agnihotri, R Khurana (2015). Emerging status of anaplasmosis in cattle in Hisar. Vet World 8:768-771

Liu Z, M Ma, Z Wang, J Wang, Y Peng, Y Li, G Guan, J Luo, H Yin (2012). Molecular survey and genetic identification of Anaplasma species in goats from central and southern China. Appl Environ Microbiol 78:464-470

Liu Z, J Luo, Q Bai, M Ma, G Guan, H Yin (2005). Amplification of 16S rRNA genes of Anaplasma species in China for phylogenetic analysis. Vet Microbiol 107:145-148

Maharana B, B Kumar, A Prasad, T Patbandha, N Sudhakar, J Joseph, B Patel (2016). Prevalence and assessment of risk factors for haemoprotozoan infections in cattle and buffaloes of South-West Gujarat, India. Ind J Anim Res 50:733-739

Makala LH, P Mangani, K Fujisaki, H Nagasawa (2003). The current status of major tick borne diseases in Zambia. Vet Res 34:27-45

Marchette N, D Stiller (2018). The anaplasmataceae, Bartonellaceae, and Rochalimaea quintana. In: Ecological Relationships and Evolution of Rickettsiae, pp:97-126. CRC Press Boca Raton, Florida, USA

Minjauw B, A McLeod (2003). Tick-borne Diseases and Poverty: The Impact of Ticks and Tick-borne Diseases on the Livelihoods of Small-scale and Marginal Livestock Owners in India and Eastern and Southern Africa, p:124. Edinburgh, UK

Nasreen KS, A Khan, S Niaz, N Akhtar (2016). Serodiagnosis and haematological effect of anaplasmosis in goats and sheep of District Mardan, Khyber Pakhtunkhwa, Pakistan. World J Zool 11:67-80

Nazar M, MA Khan, AA Shah, SU Rahman, I Khan, A Ullah, IU Khan, M Shuaib (2018). Occurrence and transplacental transmission of Anaplasma marginale in dairy cattle. Slov Vet Res 55:183-191

Nieto NC, K Khan, G Uhllah, MB Teglas (2012). The emergence and maintenance of vector-borne diseases in the Khyber Pakhtunkhwa province, and the federally administered tribal areas of Pakistan. Front Physiol 3; Article 250

Rajput Z, SH Hu, A Arijo, M Habib, M Khalid (2005). Comparative study of Anaplasma parasites in tick carrying buffaloes and cattle. $J$ Zhe Univ Sci B 6:1057-1062

Ristic M, M Levy (1981). A new era of research toward solution of bovine babesiosis (Tick control, vaccines). In: Babesiosis, pp:539-544. M Ristic, JP Kreier (Eds.). Academic Press Inc., New York, USA 
Molecular Epidemiology of Anaplasma marginale in Cattle of KP / Intl J Agric Biol, Vol 25, No 5, 2021

Rjeibi MR, O Ayadi, M Rekik, M Gharbi (2018). Molecular survey and genetic characterization of Anaplasma centrale, $A$. marginale and A. bovis in cattle from Algeria. Transb Emerg Dis 65:456-464

Rodríguez SD, MÁG Ortiz, RJ Ocampo, YCAV Murguía (2009). Molecular epidemiology of bovine anaplasmosis with a particular focus in Mexico. Infect Genet Evol 9:1092-1101

Roy B, J Krücken, J Ahmed, S Majumder, M Baumann, PH Clausen, A Nijhof (2018). Molecular identification of tick-borne pathogens infecting cattle in Mymensingh district of Bangladesh reveals emerging species of Anaplasma and Babesia. Transb Emerg Dis 65:231-242.

Saad F, M Khaisroon, K Khan, NU Akbar (2015). Prevalence and Molecular Detection of Babesiosis in the Slaughter Animals of Peshawar Khyber Pakhunkhawa Pakistan. Intl J Curr Microbiol Appl Sci 4:1030-1036
Shah S, M Khan, H Rahman (2017). Epidemiological and hematological investigations of tick-borne diseases in small ruminants in Peshawar and Khyber agency, Pakistan. J Adv Parasitol 4:15-22

Tamura K (1992). Estimation of the number of nucleotide substitutions when there are strong transition-transversion and $\mathrm{G}+\mathrm{C}$-content biases. Mol Biol Evol 9:678-687

Tay S, F Koh, K Kho, B Ong (2014). Molecular survey and sequence analysis of Anaplasma spp. in cattle and ticks in a Malaysian farm. Trop Biomed 31:769-776

Thrusfield M (2007). Veterinary Epidemiology, $3^{\text {rd }}$ Edition, pp:231-232. Blackwell Science, London, UK

Turi A, A Rahman, I Ali, SA Rafiullah, K Khan, I Shah, M Gondal, A Rashid, S Ahmed, X Wang, R Khan, SHA Raza, A Li, Y Zhang, C Liang, W Yang, S Wu, L Zan (2019). Molecular characterization of $A B H D 5$ gene promoter in intramuscular preadipocytes of Qinchuan cattle: Roles of Evil and C/EBP $\alpha$. Gene 690:38-47 